\title{
Screening for heparin binding variants of antithrombin
}

\author{
P L Harper, M Daly, J Price, P F Edgar, R W Carrell
}

\begin{abstract}
A chromogenic assay for use as a screening test for the identification of antithrombin deficiency is described. The heparin concentration and the incubation time in the assay were optimised specifically to permit the detection of heparin binding defects of antithrombin. The sensitivity of antithrombin assays for the detection of this type of variant was significantly impaired when an incubation time of more than 30 seconds was used. Several commercially available assays recommend a longer incubation time than 30 seconds and therefore some patients with heparin binding defects of antithrombin may not be identified. The assay described here allows heparin binding variants of antithrombin to be identified and distinguished from other types of antithrombin deficiency in a simple two stage procedure.
\end{abstract}

Antithrombin deficiency can either be due to a reduction in the total plasma concentration of antithrombin or to the presence of a dysfunctional antithrombin variant. Several variants have been fully characterised at the molecular level and these can be grouped into two specific types of abnormality based on their function-namely, those affecting the reactive centre of the molecule and those affecting the heparin binding site. ${ }^{1}$ Venous thrombosis is clearly associated with variants affecting the reactive centre ${ }^{2}$; the clinical importance of heparin binding variants in the heterozygous state is less clear. None the less the precise identification of heparin binding variants of antithrombin will help to elucidate the precise nature of the heparin binding site of this molecule. The initial investigation in screening for antithrombin deficiency is the measurement of antithrombin activity using a chromogenic assay. ${ }^{3}$ Several commercial assays are available, but several are unsuitable for the identification of heparin binding variants. We describe an antithrombin assay which optimises conditions for identifying heparin binding defects of antithrombin. This assay can readily be automated.

\section{Methods}

Heparin $(5000 \mathrm{IU} / \mathrm{ml})$ was purchased from Leo Laboratories; Bovine thrombin $(1000 \mathrm{IU} / \mathrm{ml})$ was purchased from Diagnostic Reagents Ltd, Thame, England; Chromozym TH (1.9 mM) was purchased from Boehringer Mannheim.
Control plasma was purchased from Immuno AG, Vienna (R78, 100\% activity). The Third British Standard (antithrombin activity$88 \%$ ) was also used as a control. Normal plasma was collected from a pool of 20 healthy volunteers and assigned a value of $100 \%$ activity. Plasma containing the antithrombin variant, antithrombin Basel, was collected from a patient undergoing investigation for recurrent venous thrombosis. The defect (41 Pro-Leu) had been confirmed by both DNA and protein sequencing. Plasma containing the antithrombin variant, antithrombin Rouen I (47 Arg-His), was a gift from Dr Y Borg. Plasma from patients with known antithrombin variants was collected into trisodium citrate ( 9 parts blood: 1 part citrate), separated, and stored at $-80^{\circ} \mathrm{C}$ until assayed.

Excess thrombin is incubated with a dilute plasma sample containing an unknown concentration of antithrombin in the presence of heparin. The residual thrombin activity, measured with a chromogenic substrate, is inversely proportional to the antithrombin activity. There are two variables which affect the sensitivity of the assay-namely, the incubation time and the heparin concentration.

OPTIMISING CONDITIONS FOR THE DETECTION OF HEPARIN BINDING DEFECTS OF ANTITHROMBIN

Antithrombin activity was measured in normal plasma, the plasma containing the antithrombin variants, and the control plasmas. Diluted plasma $(100 \mu \mathrm{l})(1$ in 50 in $0.9 \mathrm{M} \mathrm{NaCl})$ was incubated for 30 seconds, 60 seconds, 90 seconds, and 120 seconds with $100 \mu \mathrm{l}$ TRIS buffer ( $50 \mathrm{mM}$ TRIS, $100 \mathrm{mM} \mathrm{NaCl}$, pH 7.4) containing $60 \mathrm{IU} / 1$ of heparin and $4 \mathrm{IU} / \mathrm{ml}$ bovine thrombin. Chromogenic substrate (chromozym TH) $(50 \mu \mathrm{l})$ was added to the reaction mixture and the absorbance was read over 30 seconds at $405 \mathrm{~nm}$. All reactions were performed on the ACL300 (Instrumentation Lab). A standard curve was established using normal plasma at three dilutions.

The assay using heparin was performed as described above except that the incubation time was fixed at 60 seconds and various heparin concentrations were used $(0,20,60,120,1000$ IU/1).

\section{Results}

\section{INCUBATION TIME}

Plasma containing normal antithrombin inhibited thrombin maximally within 30 seconds, so the residual thrombin activity was unaffected by further prolongation of the incubation time (fig 1A). The plasma containing the heparin 
Figure $1 A$ The absorbance measured after a 30 second acquisition time in an antithrombin assay using various reaction times:

measurements made in normal plasma and plasma containing AT Basel and AT Rouen I.

Figure $1 B$ The antithrombin activity measured in plasma containing AT Basel and $A T$ Rouen I: varying the antithrombin assay. The normal range is shown in the shaded area. reaction times were used in
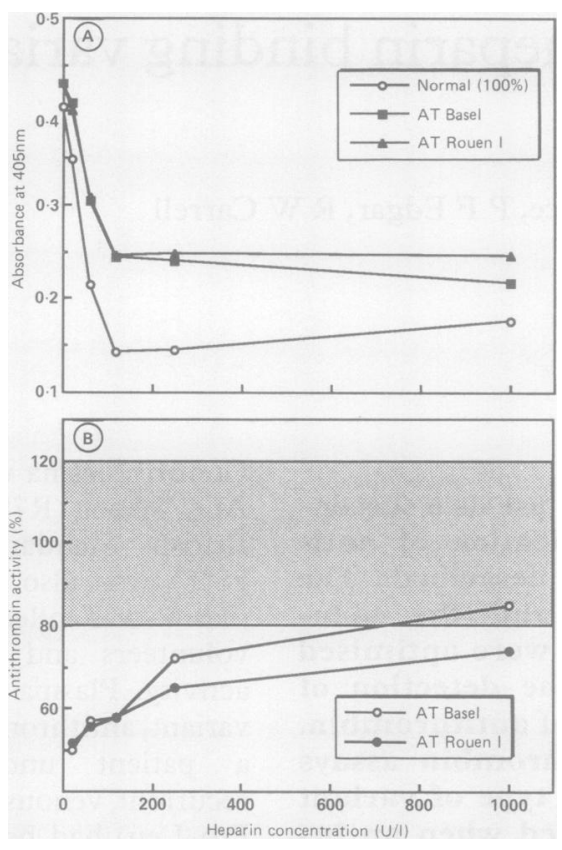

binding variants inhibited thrombin more slowly and did not reach maximum inhibition until about 90 seconds. The difference between the variants and normal antithrombin was maximal with a short incubation time ( 30 seconds) and became less apparent as the incubation time increased. A standard curve was drawn for each assay at each incubation time and the activity for the variants was calculated (fig 1B). The antithrombin activity of both variants fell within the normal range when the incubation time was greater than 60 seconds.

\section{HEPARIN CONCENTRATION}

In the presence of heparin at $20 \mathrm{IU} / 1$ and $60 \mathrm{IU} / 1$ normal antithrombin rapidly inhibited thrombin; the heparin binding variants of

Figure $2 A$ The

absorbance measured after a 30 second acquisition time in an antithrombin assay in which buffer contained various heparin concentrations. The measurements were made in normal plasma and plasma containing $A T$ Basel and AT Rouen $I$. Figure $2 B$ The antithrombin activity measured in plasma containing AT Basel and $A T$ Rouen I. Varying concentrations of heparin were used in the antithrombin assay. The normal range is shown in the shaded area. antithrombin showed less inhibition. The difference between normal antithrombin and the variants of antithrombin was most pronounced between $60 \mathrm{IU} / 1$ and $250 \mathrm{IU} / 1$ of heparin (fig 2A), as the heparin concentration increased the difference became less pronounced. Figure 2B shows the activity of the antithrombin variants calculated at each heparin concentration from the standard curves. The activity of plasma containing antithrombin Basel fell within the normal range when buffer contained heparin at $1000 \mathrm{IU} / 1$.

\section{Discussion}

The incidence of antithrombin deficiency is between 1 in $2000^{4}$ and 1 in $5000 .^{5}$ The incidence of antithrombin variants with reduced heparin affinity, however, is unclear, and many cases may have been overlooked due to the use of insensitive assays. Heparin binding defects of antithrombin are characterised by normal progressive activity, which is reduced in the presence of heparin-that is, reduced heparin cofactor activity. This loss of heparin affinity is due to a mutation affecting the heparin binding site of antithrombin. ${ }^{1}$ We have used two known heparin binding variants, antithrombin Rouen 1 (47 Arg-His), ${ }^{6}$ and antithrombin Basel (41 Pro-Leu), ${ }^{7}$ to optimise a chromogenic assay to permit the identification of these types of variants.

Two variables affect the sensitivity of assays for identifying antithrombin defects with reduced heparin affinity-namely, the heparin concentration and the length of the incubation time. The assay was most sensitive with a short incubation-that is, 30 seconds-and lost sensitivity as the incubation time increased. Consequently if an assay with an incubation time of more than 60 seconds is used, some antithrombin variants would be overlooked (fig 1B). The heparin concentration seems to be a less critical variable and the assay only lost sensitivity when the heparin concentration exceeded $1000 \mathrm{IU} / 1$.

Commercially available antithrombin kits recommend an incubation time varying from 30 seconds (Kabi) to five minutes (Boehringer Mannheim). Similarly, the preset programmes on some automated analysers have an incubation time greater than 30 seconds-for example, the ACL 300 has an incubation time (reaction time) of 90 seconds. Therefore, some of these assays are unsuitable as a screening test to identify all types of antithrombin deficiency. We recommend an assay using buffer containing heparin at $60 \mathrm{IU} / 1$ and an incubation time of 30 seconds. If the plasma antithrombin activity is low using this assay the heparin binding defects of antithrombin can be differentiated from other antithrombin variants by repeating the assay with a longer incubation time (150 seconds), but keeping all other variables unchanged. Plasma containing a heparin binding defect will have low antithrombin activity in the assay with a short incubation time and significantly higher activity (a rise of at least $20 \%$ ) in the assay with a longer incubation time. Plasma containing other antithrombin 
defects will give consistently low activity results with both the short and long incubation times.

We gratefully acknowledge the support of the British Heart Foundation, the Wellcome Trust, and the Medical Research Council. We also thank Dr Y Borg for the gift of plasma containing the Rouen I variant of antithrombin, and for her advice.

1 Prochownik EV. Molecular genetics of antithrombin III deficiency. Am J Med 1989;87(suppl 3B):15S-18S.

2 Thaler E, Lechner K. Antithrombin III deficiency and thromboembolism. Clin Haematol 1981;10:369-90.
3 Abildgaard U, Lie M, Odegard OR. Antithrombin (heparin Cofactor) assay with 'new' chromogenic substrate. Thromb Res 1977;11:549-53.

4 Rosenberg RD. Action and interaction of antithrombin and heparin. N Engl J Med 1975;292:146-52.

5 Abildgaard $U$. Antithrombins and related inhibitors of coagulation. In: Poller L, ed. Recent advances in blood coagulation. Vol 3. Edinburgh: Churchill Livingstone, 1981:151-73.

6 Owen MC, Borg JY, Soria C, Soria J, Caen J, Carrell RW. Heparin binding defects in a new antithrombin variant: Rouen 47 Arg to His. Blood 1987;69:1275-9.

7 Chang JY, Tran TH. Antithrombin III Basel. Identification of a Pro to Leu substitution in a hereditary abnormal antithrombin with impaired heparin cofactor activity. $J$ Biol Chem 1986;261:1174-9. 